\title{
Strategy Research on the Green Development Standard System for Intellectual Property Services
}

\author{
Zongzhen Jin, Zongling Wang, Lili Cao \\ China National Institute of Standardization, Beijing, 100191, PR China.
}

Keywords: Intellectual property rights; green economy; service.

\begin{abstract}
With development of intellectual property (IP) industry, the standard system is needed to build to solve the nonstandard behavior of intermediary service organization, especially for the development of green economy. Through construct the structural diagram for chains and functions of IP services, the government and market role and function is analyzed. Based on the status quo of industrial development and previous standardization study, green development standard system of intellectual property services for commercial use is established. At last, some suggestion is put forward.
\end{abstract}

\section{Status Quo of Standardization of IP Services}

In recent years, the speed of scientific and technological innovation in China has continued to accelerate, and the intellectual property right cause has ushered in a new development period. In terms of patents, in 2017, China applied for 1.382 million patents of invention, ranking the first in the world for seven consecutive years. The total amount of patent financing was 72 billion Yuan. A total of 67,000 cases of patent administrative law enforcement took place. Over 1,824 patent agencies were set up in China and there were more than 16,000 practicing patent agents. In terms of trademarks, in 2016, 3.691 million cases of application trademark registration were accepted, a YOY increase of $28.4 \%$, ranking the first in the world for 15 consecutive years. Chinese applicants submitted 3,014 cases of application for international trademark registration in Madrid, a YOY increase of 29.8\%. The overall amount of trademark financing was 65 billion Yuan. In terms of other types of IP, 2.008 million cases of copyright registration took place, a YOY increase of $22.3 \%$, and 2,011 cases of new plant variety rights were granted, a YOY increase of $35.2 \%$.

IP services cover intellectual property agency services, legal services, information services, commercial services, consulting services, and training services. As new types of services, IP services obtain, use and safeguard different types of IP including patents, trademarks, copyrights, commercial secrets, new plant varieties, and IP in specific fields. They also include some derivative services and promote transformation of intellectual accomplishments into rights, commercial use and industrialization. IP services are important components of the modern service industry and also important domains of development of the high-tech service industry. They are important for national economic development and also are important parts of the science and technology service industry. They provide information consulting, intellectual property agency services, and commercial use of intellectual property rights for technology $R \& D$ of all industries in the national economy. Just take patent information consulting as an example. More than 60 million patent documents have been released worldwide, and over one million of new ones will emerge every year. A large number of basic information resources are provided for promoting social and enterprise innovation. According to the statistics of the World Intellectual Property Organization (WIPO), 90\% to 95\% of the world's invention achievements every year can be searched in patent literatures. The technology and methods contained in these patent literatures can help to shorten $40 \%$ of the time and reduce $60 \%$ of the expenditures in scientific researches.

With the development of IP services, a lot of problems arise. The overall scale is small, the quality of services is low, the management of service organizations is not standard, and not all practitioners are qualified. At the same time, IP service standards are insufficient and no standards have been worked out for IP service organizations and practitioners. These problems not only harm management 
of service organizations and practitioners but also hinder healthy and rapid development of IP services. There is an objective need to develop a series of IP service standards to help the development of the IP service industry. Furthermore, a lot of efforts are made to accelerate the development of green economy, which a new modes of sustainable growth are building in China. It needs the intellectual property service organizations to support the development green economy. All these measures can hardly do without the help the intellectual property service standard system.

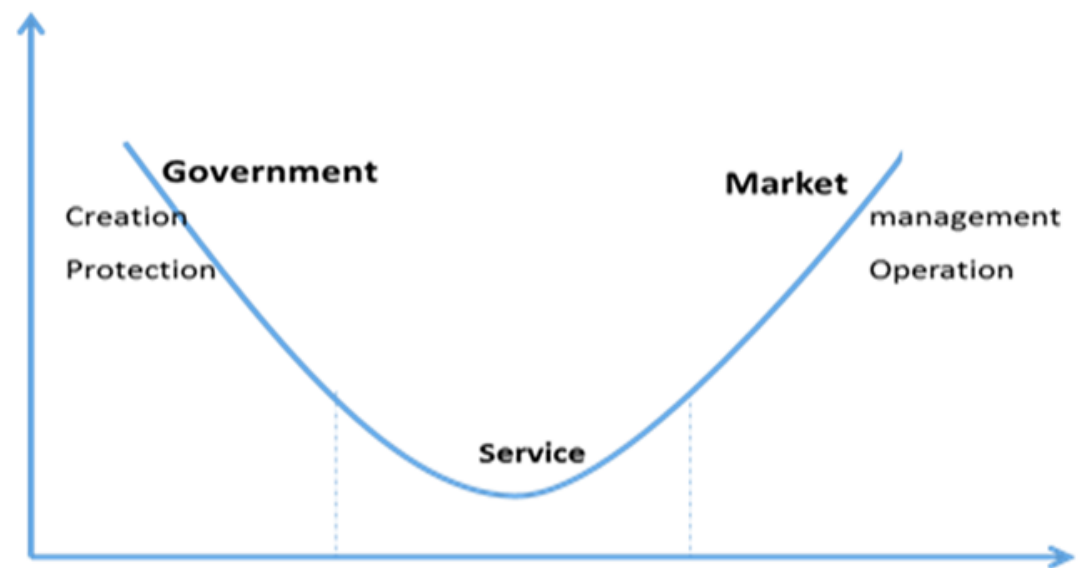

Fig 1. Structural diagram for chains and functions of IP services

Intellectual property service standards are based on the whole process of creating, applying, managing, and protecting IP. They regulate behaviors of public welfare service organizations, commercial service organizations, and practitioners that provide IP. They help to improve the quality of processes of providing services, realize procedural, standardized and unified IP services, and enhance the benefits and quality of the transfer and transformation of scientific and technological achievements. Based on these, the standards further promote innovation and development of the society and enterprises and stimulate the industrial development of IP services to form actual productive forces and provide high-quality comprehensive IP services in establishment of an innovative country.

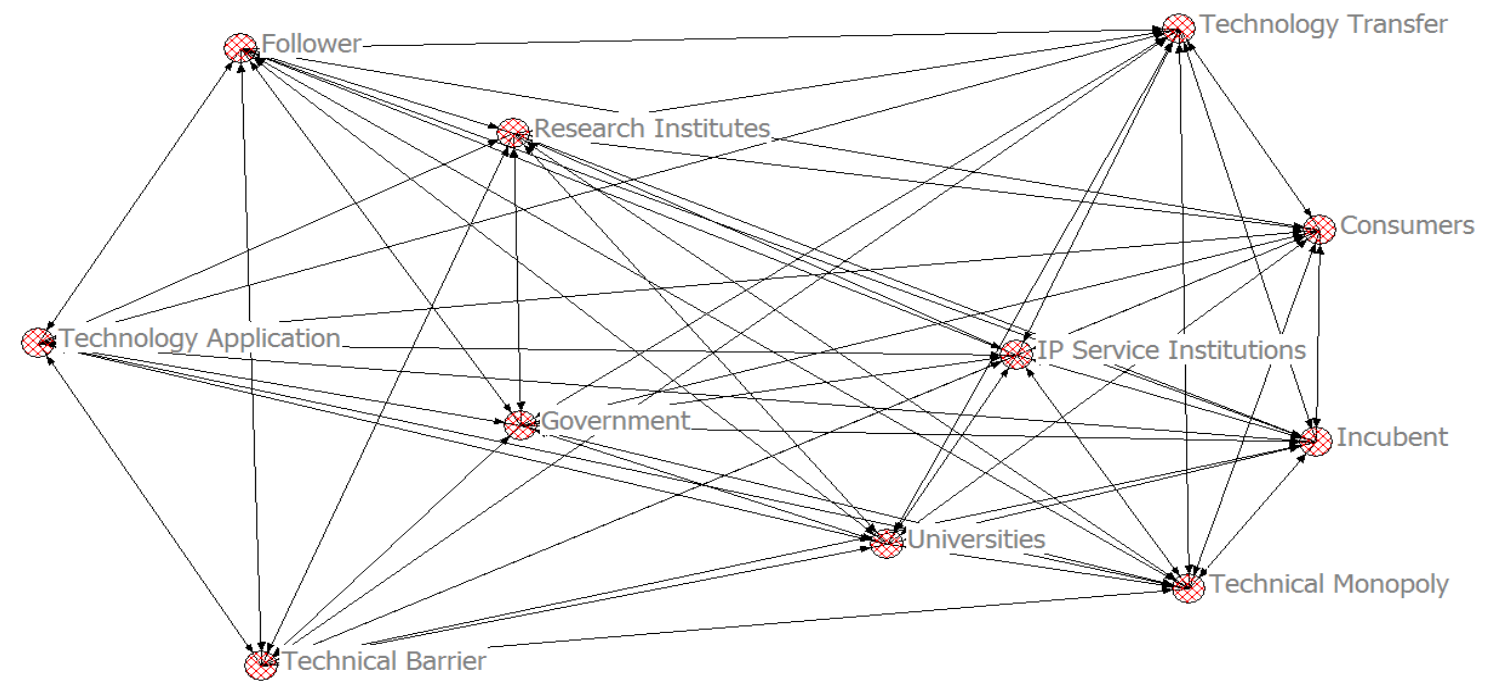

Fig 2. Relation of IP service institutions and innovation elements

From the figure, we can find that IP service institution help universities and research institutes to apply for patent and other kinds of IP, change the market situation of incumbent and follower, and break the technical monopoly and technical barrier. The IP granted will be transferred to the industrial application, which is great helpful to promote the industrial upgrading. IP service institution plays the crucial role in constructing the industrial innovation, which also can be used in the green industry. 
The green standardization of IP plays an important role in standardizing service processes, improving service quality and efficiency, and improving user satisfaction, ensuring service security, improving market environment, and promoting service trade development. It is an urgent need to strengthen the standardization of IP services, develop standards and plans for IP services, develop standards for the fields of IP services, support the formation of a group of independent IP of core technologies that play a major role in green economic and social development, form a group of wellknown brands with independent IP and improve the ability to use and protect these IP in a bid to enhance independent innovation capabilities of Chinese enterprises and core competitiveness of China.

\section{Domestic and Overseas Development of the Standard System for IP Services}

The standard system for IP services is an important means to promote healthy development of IP services. It plays an important role in standardizing IP service behaviors, improving service quality and efficiency, enhancing service capabilities, improving market environment and strengthening selfdiscipline. To promote the standardization of IP services, establish and improve the standard system for IP services, and improve the quality and efficiency of IP services, the State Intellectual Property Office, the National Standards Committee, the State Administration of Industry and Commerce, and the Copyright Administration jointly developed the Guidelines on Establishment of the Intellectual Property Right Service Standard System and actively promoted the establishment of the standard system at the end of 2014. In 2016, the State Council issued the Plan for the Protection and Application of Intellectual Property Rights in the "Thirteenth Five-Year Plan". It clearly stated that it would be necessary to establish the standards of IP services and improve the IP service system. It proposed to establish a technical organization for standardization of IP services, promote the development of the service standard system, and carry out the pilot demonstration of standardization. It also specified the direction and objectives of the standardization of IP services in China during the "Thirteenth Five-Year Plan" period.

In recent years, the State Intellectual Property Office has organized relevant departments to draft and release three national standards such as GB/T 32089 Intellectual Property Right Management in Scientific and Technologic Research Projects, GB/T 33250 Standard on Intellectual Property Right Management in Scientific and Technologic Organizations, and GB/T 33251 Standard on Intellectual Property Right Management in Universities. It is also developing other national standards, including Intellectual Property Analysis and Comments and GB/T34833-2017 Standard on Patent Agency Services. In local regions, the standardization of IP services has also been promoted. In recent years, the Intellectual Property Office of Shaanxi has formulated the first public service standard system of intellectual rights in China. In terms of patent and IP institutions, Ningbo, a city in Zhejiang, took the lead in developing the Standard on Patent Information Services in Ningbo. Beijing and Jiangsu are developing the Standard on Quality of Patent Agency Services and the Standard on Intellectual Property Right Analysis and Comments. Liaoning has worked out the Standard on Intellectual Property Right Institution Management. Jiangsu has released the Standard on Intellectual Property Right Financing. Shenzhen Guangdong has set up the Institute of Standards and Intellectual Property Right and released several local standards such as the Standard on Patent Agency Services, the Intellectual Property Warning Guidance of Overseas Exhibition for Enterprises, the Guidance on Analysis and Use of Patent Information, and the Technical Specification for Evaluation of Intellectual Property Right Mortgage. In terms of trademarks, Shanghai has released the Standard on Trademark Agency Services, Jiangsu has released the Standard on Trademark Management of Enterprises, and Guangdong has released the Standard on Trademark Agency Services. The promotion of the above standards for IP services is a useful exploration for the overall establishment of the standard system for IP services in China. The notion of green patent was put forward in order to promote the ecological industry development in 2017, which attracted the attention of the scholars. Also the green standard system of intellectual property service is also needed in practice to support

Due to the increasingly prominent role of IP in the development of innovation, developed countries have gradually realized the importance of IP service standards. In 2011, the British Standard 
Association released the Specification for the provision of Services Relating to the Commercialization of Intellectual Property Rights (BS 8538-2011), which aimed to clarify the ethics and behavior norms of inventor-oriented IP service organizations, and standardize the service behaviors and ethical guidelines of IP practitioners and organizations. It also involved consultants, invention brokers and inventor protection agencies related to the commercialization of IP. In the same year, Germany's Standardization Society released the General Rules for Patent Valuation and Patent Valuation Currency (DIN 771000-2011). It put forward the basis of patent valuation, six main principles, and the legal, technical and economic factors that affect patent valuation. It also standardized patent valuation procedures and methods as well as the applicable scope and three methods such as income, market and costs. In addition, Germany released the Service Quality in Intellectual Property Management (DIN SPEC 1060-2010) in 2010, which standardized the service quality of patents, trademarks, and utility models in terms of service life cycle, patent attribute, patent protection, quantity detection, and service facilities, and raised up requirements for IP service organizations and practitioners. Based on the preceding analysis, it is found that the German standards mainly involved some technical specifications for evaluation, but did not cover the evaluation personnel's behavior specifications, such as professional ethics. It is also found that the UK standard mainly involved some behavior specifications to be followed in IP services but did not mention any specific service contents or technical standards to be followed. In terms of content, this standard is somewhat analogous to the Model Rules of Professional Conduct of the American Bar Association.

In conclusion, China has been exploring a lot in amending industrial standards of the IP industry. The demand for standardization in the industry and local places has gradually emerged, which will help to improve the level of IP services and promote the healthy development of the IP service industry in China. However, in the process of developing IP service standards in China, there is a lack of unified national standards. Although standards of IP services are formulated by provinces, cities and various associations, they are scattered. It is in an urgent need to accelerate the development of relevant standards of IP services and improve the standard system for IP services.

\section{Basic Path for Establishing the Green Development Standard System for IP Services}

The establishment of the standard system for IP services in China should put focus on the whole chain in the development of the IP industry, especially in the green industry. From the aspects of creation, management, application and protection of IP, we can refer to six key development areas and seven types of specific public services concerning IP. We can follow the basic standard, the business support standard and the service supply standard in the Guidance on Accelerating Nurturing and Development of the Standard System for Intellectual Property Rights. By considering seven types of services including IP agency services, legal services, information services, commercial services, consulting services, training services and public services as well as attributes of services and types of business that IP agencies are engaged in, we should establish the standard system of intellectual property services for commercial use based on IP service agencies.

The establishment of the IP service system is based on the development status and trend of the IP service industry in China, especially under the strategy of innovation-driven development.

Furthermore, as the moment that people has realized the importance of the environment protection, the green industry is expanding rapidly. The number of green industry patents application is growing very fast. At the meantime, intellectual property service organizations accept many invention applications, which need the pattern to serve the green industry companies. While as green IP examining procedure the same as the other kinds, IP standard system also is suitable for the green economy IP development. 


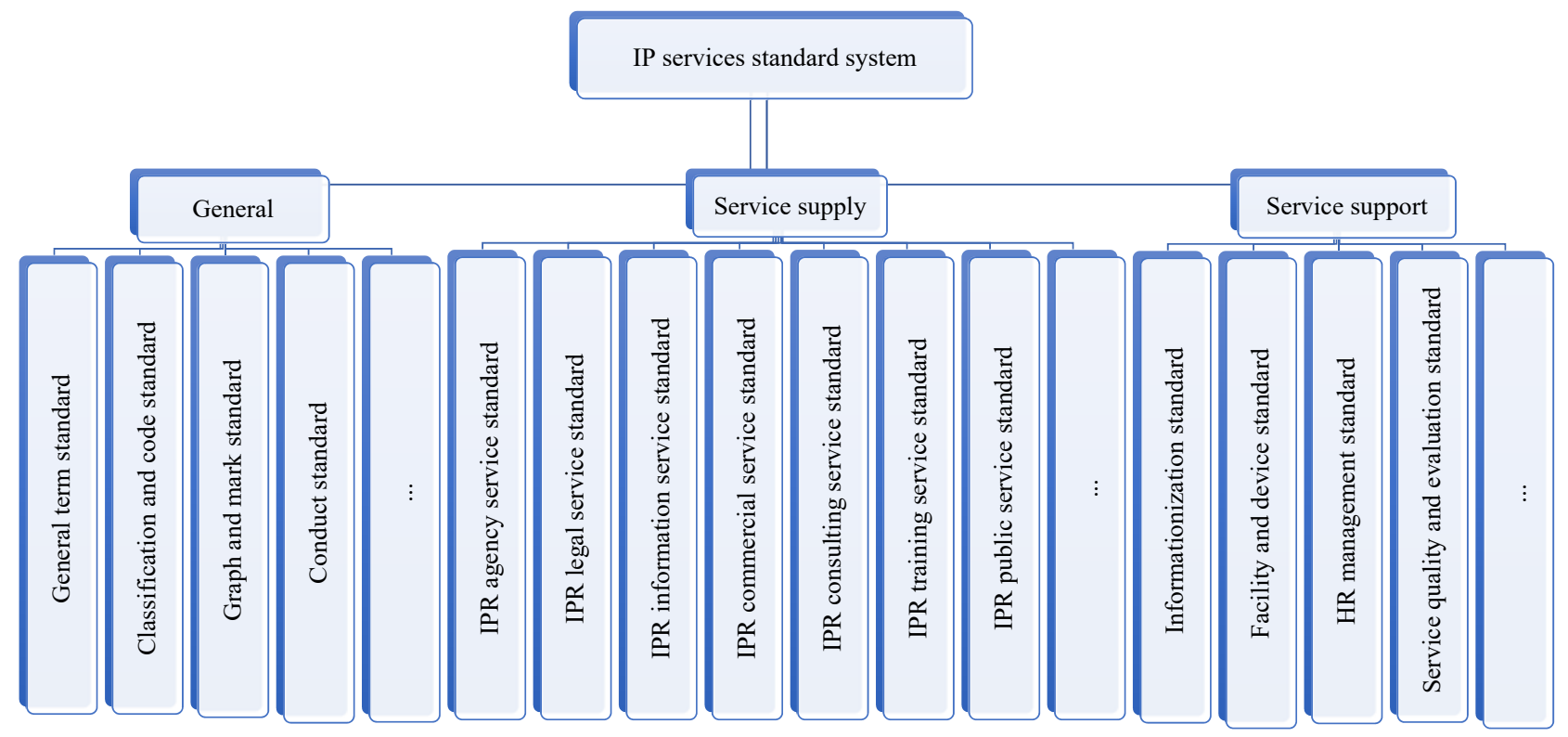

Fig 3. Structural diagram for the IP service system

In the background that the IP strategy is promoted in various local regions and that different local standards are formulated, we need to "play a good game of chess" from the macro-level of the country, coordinate the common development of IP services in China, and build a scientific, reasonable, clear, and orderly IP service standard system based on key difficulties and hot spots of the current development of IP services. In this way, we will break through the bottleneck of the development of scientific and technologic innovation, stimulate the transfer and application of science and technology to market products, and achieve industrialization and marketization of technological achievements, thus promoting the rapid and healthy development of the IP service industry.

We should build a standard system for IP services, develop standards for key IP fields, and combine national standards, industry standards, group standards and enterprise standards in the fields of IP services. We adhere to the overall macro layout, systematic improvement, and effectively implementation of standards. According to the actual situation of the industry development requirements of the IP service industry, we should prioritize the establishment of standards with urgent needs of standardization. Meanwhile, we should adopt the principle of prudence. We will promote the application of these standards after the standard system becomes relatively mature, and will also coordinate the interest of many different parties. We should make joint efforts to promote the establishment of the IP service standard system.

To sum up, this article puts forward some suggestions on implementing standards from both macro and micro angles in practice of the standardization of Chinese IP services based on the status quo of IP service development, especially the practice of IP standardization at home and abroad. The implementation of the IP service standards should be based on the outstanding characteristics of the technology service industry and the establishment of standards. Based on the standardized implementation procedures, it should prioritize both macro and micro nodes in the implementation of standards. We should coordinate and pay attention to details so as to create a friendly environment to guarantee systematic, constant and interactive implementation of IP service standards. The implementation is a growing process, which needs to be improved gradually according to the development of the IP service industry. Only the standard system and standards that are dynamically developed can help to implement high-quality intellectual property service standards.

\section{References}

[1]. Feng Jibe and Hour Fee. Study of intellectual property service standization strategy [J]. China Standardizaiton. 2015.01. 
[2]. Zhou Yan. Thinking of scientific and technological intermediary service system in British [J]. Quantic Keri Jigjig Liaoyang. 2009.05.

[3]. Hour Fee, Yang Shoo and Wan Faun. Studies on establishment of standard system of high-tech services industry [J]. China Standardization. 2012.12.

[4]. Liu Juan and Ma Bin. Intellectual property industry is needed in China [J]. China Invention \& patent. 2012.05.

[5]. Jin Zongzhen and Liu Habit. Invention Patents Are Not for Everyone: Developing Less Industrialized Regions in China with 'Light' Intellectual Property, Economic Impacts on Intellectual Property-Conditioned Government Incentives [A]. Economic Impacts of Intellectual Property-conditioned Government Incentives[C]. Singapore: Springer. 2016:309-328. 